inventing them. And it is conceivable that they may have the further anguish of seeing an effectual chemical remedy made the basis of a fiendish weapon. Clearly all this poses problems to the medical profession very different from those entailed by the development of "conventional" weapons from the knobkerrie to the high-explosive bomb. A doctor did not have to understand the structure of a shell or the composition of an explosive to treat the wounded successfully.

The first use of modern chemical warfare was in 1914, when the French hurled grenades filled with tear gas and the Germans retaliated with tear-gas artillery shells. ${ }^{3}$ In 1915 the Germans launched an attack with chlorine, the first lethal gas to be used. Thereafter the belligerents on both sides used phosgene and mustard gas as well. Nowadays anticholinesterase agents are regarded as the most effective, causing death by convulsions and respiratory paralysis, but fortunately they have never been used. Research into biological weapons has entailed studies of many well-known viruses and rickettsiae as well as the properties and toxins of various bacteria. Yet as V. W. Sidel and R. M. Goldwyn remark in their account of this work, "There has been remarkably little public debate, particularly among physicians, on the advisability of developing, stockpiling, and using chemical and biologic weapons." And Sidel ${ }^{4}$ has called again for these questions to be "actively debated" soon.

On the part the physician himself should play in these terrible activities to which man has set his hand the Declara- tion of Geneva offers pertinent advice. One of its clauses reads as follows: "I will maintain the utmost respect for human life from the time of conception; even under threat, I will not use my medical knowledge contrary to the laws of humanity."' In deciding whether his work conforms to the profession's accepted ethical traditions, of which the Declaration of Geneva forms a part, a doctor must be allowed to consult his own conscience, for codes of ethics are not juridical instruments prescribing rules of conduct in legal terms. But it would seem that the secrecy which is apt to surround defence work may be as much a source of embarrassment to doctors employed on it as of suspicion to people who are not. Certainly complete freedom to publish results can be a valuable safeguard to the good name of an investigator, and indeed of all medical men. For it is worth stressing here that the profession as a whole has a responsibility to consider the ethical problems that confront it and to take part as a whole in the continual restatement of them in accordance with changing needs. The relatively small number of men upon whom the great ethical challenges of our time necessarily fall should not be expected to meet them in isolation, though the experience informing their views must clearly deserve special attention.

Clegg, H. A., Brit. med. 7. Suppl., 1958, 1, 341.

' Ormrod, Sir R., Brit. med. F., 1968, 2, 7.

3 Sidel, V. W., and Goldwyn, R. M., New Engl. Ұ. Med., 1966, 274, 21

- Sidel, V. W., Lancet, 1968, 1, 966.

B.M.A. Members Handbook, 1965. British Medical Association.

\section{Nasal Cancer in Woodworkers}

At page 587 of the B.M.F. this week Dr. E. D. Acheson and his colleagues describe an association between occupation as a woodworker in the furniture industry, and risk of developing adenocarcinoma of the nasal cavity and sinuses. The work should not be passed over simply because it refers to a form of cancer that is relatively rare in the United Kingdom. The report indicates that the incidence of 0.7 cases of nasal cancer per 1,000 wood machinists is about the same as that for carcinoma of the bronchus in men or carcinoma of the breast in women in the general population. The main features of the condition are a predilection for the ethmoid sinus and an average induction time of about 40 years. Despite this apparently long interval, a substantial number of the cases reviewed by Acheson and his colleagues were less than 55 years old at the time of diagnosis.

Since the risk was present as early as 1920 , it is unlikely that processes and chemicals introduced during or after the second world war are implicated. The risk seems to be confined to workers exposed to wood dust, for Frenchpolishers, varnishers, and upholsterers, whose tasks require them to work in separate, non-dusty, premises, experience only the normal incidence of nasal adenocarcinoma. Because carpenters and joiners, most of whom work with soft woods, are apparently not affected, Acheson and his colleagues deduce that the risk may relate especially to the inhalation of one or more of the hard woods, such as beech or oak. This last conclusion, however, may be unwarranted in so far as the precision and fine finish required in cabinet-making cause men to be exposed to wood dust much finer and more readily inhaled than normally falls from the carpenter's saw. Not taking account of this important difference in type of exposure between cabinet-makers and other woodworkers may partly account for M. J. Ball's ${ }^{1}$ finding no excess of nasal cancer in Canadian woodworkers, though other factors may also have

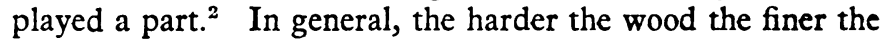
dust, but those who work with wood, hard or soft, find the dusts of some trees-for example, Italian walnut, certain mahoganies, and western red cedar-more irritant than others. It will be important to try to ascertain whether the

Ball, M. J., Lancet, 1967, 2, 1089.

2 ., Lancet, $1967,2,1089.1310$

- Muir, C. S. and Shanmugaratnam, K. (eds.), Cancer of the Nasopharynx, 1967. Copenhagen.

Dobson, W. H., China med. f., 1924, 38, 786

Digby, K. H., Fook, W. L., and Che, Y. T., Brit. 9. Surg., 1941, 28 517.

Scott, G. C., and Atkinson, L., Cancer of the Nasopharynx, ed. C. S. Muir, and K. Shanmugaratnam, 1967. Copenhagen.

' Clifford, P., E. Afr. med. F., 1965, 42, 373.

'Clifford, P., and Bulbrook, R. D., Lancet, 1966, 1, 1228.

- Wang, D. Y., Bulbrook, R. D., and Clifford, P., Lancet, 1966, 2, 1342.

Shapiro, M. P., Keen, P., Cohen, L., and de Moor, N. G., S. Afr. med. 7., 1955, 29, 95.

Keen, P., Clin. Radiol., 1963, 14, 250.

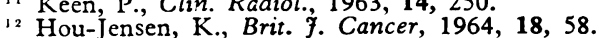

Lou-Jensen, K., Brit. F. Cancer, 1964, 18, 58.

4 Yeh, S., Cancer of the Nasopharynx, ed. C. S. Muir and K Shanmugaratnam, 1967. Copenhagen.

is Druckrey, H., Ivankovic, S., Mennel, H. D., and Preussman, R., Z Krebsforsch., 1964, 66, 138.

16 Thomas, C., Z. Krebsforsch., 1965, 67, 1.

17 Snell, K. C., and Stewart, H. L., quoted by Dawe, C. J., in Cancer of the Nasopharynx, ed. C. S. Muir and K. Shanmugaratnam, 1967 Copenhagen.

\& Dawe, C. J., in Cancer of the Nasopharynx, ed. C. S. Muir and K Shanmugaratnam, 1967. Copenhagen.

Acheson, E. D. Hadfield, E. H., and Macbeth, R. G., Lancet, 1967, 1 311 .

Milham, S., and Hesser, J. E., Lancet, 1967, 2, 136.

Acheson, E. D., Lancet, 1967, 2, 988. 
hazard relates to wood dusts generally or only to the dusts from specific woods.

In other parts of the world, notably China, Malaysia, Indonesia, and East Africa, nasopharyngeal cancer is more frequent than in the United Kingdom. ${ }^{3}$ It seems unlikely, however, that the aetiological factors in these areas, such as incense smoke, smoke from domestic wood fires, ${ }^{5}$ and racial, $^{6}$ anatomical, ${ }^{7}$ nutritional, ${ }^{7}$ or possibly hormonal ${ }^{8}{ }^{9}$ factors, affect furniture makers in the Oxfordshire and Buckinghamshire area of England, and Acheson and his colleagues have virtually excluded snuff-taking ${ }^{10-12}$ as a factor. According to C. A. Linsell ${ }^{13}$ and S. Yeh ${ }^{14}$ only a small minority of the nasopharyngeal cancers in Kenya are adenocarcinomas, and in China the epidermoid type of tumour is even more predominant. Other agents known to cause nasopharyngeal cancer in man, notably nickel, radium, and isopropyl alcohol, have no place in furniture manufacture, and the only possibly relevant lead from the laboratory at present is the discovery that tumours of a variety of histological types, including adenocarcinoma, may be induced in the nasal cavities of rats by exposure to certain nitrosamines, ${ }^{15}{ }^{16} \mathrm{~N}, N^{\prime}-2,7$-fluorenylenebisacetamide, ${ }^{17}$ or polyoma virus. ${ }^{18}$

After a preliminary report by Acheson and his colleagues ${ }^{19}$ a possible association between woodworking occupations and death from Hodgkin's disease was reported. ${ }^{20}$ Acheson, ${ }^{21}$ however, was unable to find a similar association in relation to his material.

The replacement of the skilled craftsman by machinery and the introduction of ventilation to extract dust in larger factories has transformed the furniture industry during the past 30 years, so that the hazards to health are now probably very different from what they were before the war. It is therefore a matter of urgency that further studies as careful as that of Acheson and his colleagues, but on different furniture-making communities, be undertaken in order to detect more precisely the carcinogen or carcinogens at work.

\section{Care and Training of Handicapped Children}

It has often been said that a sensitive index of any nation's level of cultural development is the provision it makes for its handicapped children. Britain makes the proud claim that in this respect it leads the world.

A recent number of Medical and Biological Illustration ${ }^{1}$ is devoted to a review of existing provisions for the diagnosis, treatment, supervision, and education of handicapped children from early childhood to school-leaving age. The issue includes papers on the role of a developmental-paediatrics centre and on schools for children suffering from blindness, impaired hearing, deafness with maladjustment, delicate children, and children with physical handicaps of various sorts, including a hospital school for children with epilepsy. There is also a delightful paper on gardening as an appropriate hobby for handicapped children, who tend to spend too much of their lives indoors. It concludes with an editorial, a list of recommended readings, and a selection of book reviews. The illustrations are admirably chosen and splendidly produced.

Taken as a whole, the collection of papers raises a number of questions still open to discussion about the changing views of educational experts, school medical officers, and paediatric consultants on special educational treatment. At the beginning of the century, when special schools first came into existence, the cure or mitigation of some clearly defined handicap was the first thought, so that attention was concentrated on treating the disorder, sometimes at the expense of the child's education. Later, the child's developing personality and intellect received more attention, but the presenting handicap still got priority in his education. But during the past decade it has increasingly been recognized that careful evaluation and training of the child's individual assets are of paramount importance at school and in life. It is generally agreed that, while the proportion of handicapped children requiring special arrangements remains much the same as formerly, the nature of their handicaps (and therefore their needs) is more complicated. Medical progress, which has prevented or cured many conditions which formerly necessitated extensive special educational provisions, has also kept alive many children with more severe and complex multiple handicaps who formerly would have died. In one sense it may be argued that every handicapped child, whatever his presenting disability, is multi-handicapped, because he is at a disadvantage socially, emotionally, or intellectually. But there is no doubt that the existing list of more or less mutually exclusive categories of handicaps has become unrealistic. There seems, therefore, to be a strong case for a detailed review of the whole question of formal ascertainment for special education and for a fresh look at the special schools themselves. Since he must eventually live in the ordinary community, a handicapped child should if possible attend an ordinary school, but this may not always be practicable for educational, social, or geographical reasons. These may not always be apparent to uninformed people, including the child's own family.

The first need is for improved diagnostic services, so that any child suspected of deviating from the normal course of physical, intellectual, emotional, or social development may be provided with the special treatment he requires at the most appropriate stage. Specially designed buildings, though essential for certain groups of handicapped children, are not so important as specially trained and experienced teachers, educational psychologists, and school medical officers, all of whom are scarce. It is doubtful if more special schools are needed, but more special day centres and classes attached to ordinary schools are. They should be provided for children of all ages, beginning with nursery units for children from 3 years upwards. In these units it would be possible not only to study the children's individual needs more completely, but also to give the parents better guidance on home management and to keep them completely informed about the child's progress and what plans should be made for his future.

When a child must be educated away from home every effort should be made to send him home for week-ends and to return him to a suitable day school as soon as possible. Family doctors and school medical officers concerned should consider it a duty to maintain relations with him and his family during holidays, and, when he returns to the ordinary school, to make sure that he is adequately followed up. Finally, it must always be kept in mind that the finest diagnostic provisions are of little use to any handicapped child or to his parents unless the appropriate welfare services are always readily available to them.

\footnotetext{
' Med. biol. Ill., 1967, 17, No. 4.
} 